\title{
Construction and integrated analysis of ceRNA networks identified survival-related genes in gastrointestinal tumors
}

Dan Bai ( $\nabla$ danbai@xjtu.edu.cn )

Northwestern Polytechnical University

Huhu Feng

Northwestern Polytechnical University

Jiajun Yang

Northwestern Polytechnical University

Haitao Shi

Second Affiliated Hospital of Xi'an Jiaotong University

Fanpu Ji

Second Affiliated Hospital of Xi'an Jiaotong University

Hiroshi Sugiyama

Kyoto University

Keywords:

Posted Date: May 10th, 2021

DOI: https://doi.org/10.21203/rs.3.rs-432424/v1

License: (1) This work is licensed under a Creative Commons Attribution 4.0 International License. Read Full License 


\section{Abstract}

The authors have requested that this preprint be removed from Research Square. 